\title{
The Research of Heating System Savings Calculation Method
}

\author{
Dan $\mathrm{Yu}^{1 \mathrm{a}}$, Ran $\mathrm{Li}^{1}$, Zeyu Liu ${ }^{1}$ \\ ${ }^{1}$ Beijing University of Civil Engineering and Architecture, Beijing, China \\ ayudan@bucea.edu.cn
}

Key words: savings calculation, heating system, model method

Abstract. By analyzing and comparison savings calculation method of the heating system, the writer conclude the appreciate calculation methods for different conditions, and find that the method of baseline energy consumption-influencing factors can accurately reflect the energy consumption of heating system. Establish the mathematical model of baseline energy consumption-influencing factors, calculate the energy savings and make the uncertainty analysis.

\section{Introduction}

With the rapid development of our economy, energy problem becomes more and more obvious. According to statistics, China's building energy consumption accounts for about $33 \%$ of the total energy consumption ${ }^{[1]}$. In recent years, the transformation project of existing building heating system has increased year by year, but lack of unified scientific energy saving calculation method. This paper introduce and compare these existing energy saving calculation methods, combine with the engineering example, test and validate the most suitable method for energy saving calculation of heating system.

\section{The Calculation Method of Energy Saving}

At present, there are four main methods for energy saving calculation: the model of baseline energy consumption-influencing factors, the software simulation method, the direct measurement method and the engineering calculation method. The model of baseline energy consumption-influencing factors should base on the dates of consumption before retrofits and external condition, then establish the model of baseline energy consumption-influencing factors, through the model, this baseline relationship was used to estimate how much energy the plant would have used each month if there had been no energy conservation measure, and it is called the "adjusted-baseline energy. The saving is the difference between the adjusted-baseline energy and the energy that was actually metered during the reporting period. This method is widely used; the method considers not only the actual project situation but also influence of the change of external conditions on energy consumption. It is suitable for the calculation of complex system, but requires a large amount of data to ensure the accuracy of the model.

\section{Engineering Case Analysis}

Introduction to the Project. A beating group in Beijing services a total area of about $2570000 \mathrm{~m}^{2}$, the raw coal consumption is 81837 tons during the heating season of 2011-2012, reduced to 31.84 $\mathrm{kg}$ per unit area. The low heating value is $23.282 \mathrm{MJ} / \mathrm{kg}$, the total raw coal consumption is 65014.98tons, reduced to $25.30 \mathrm{~kg}$ per unit area. After retrofits, the service area is $270 \mathrm{million} \mathrm{m} 2 \mathrm{in}$ the heating season in 2012-2013; the raw coal consumption is 705571 tons reduced to $26.13 \mathrm{~kg}$ per 
unit area. The low heating value is $25.628 \mathrm{MJ} / \mathrm{kg}$, the total raw coal consumption is 61696.62 tons, reduced to $22.85 \mathrm{~kg}$ per unit area.

The monthly coal consumption data and weather parameters of 2011-2012 and 2012-2013 of this project are provided; the model of baseline energy consumption-influencing factors should be chosen to calculate the saving.

Methods Analysis. The range of this retrofit is large, and the energy saving effect is affected by weather factors, equipment operation is changed complex, and the boundary is complicated, therefore, direct measurement method and simple engineering calculation method is not applicable. If using the simulation method, it is hard to establish the simulated model, accompanied by error, so the simulation method is not applicable.

Using the model of baseline energy consumption-influencing factors is the most suitable method.

Establish the Model of baseline energy consumption-influencing factors. For the heating engineering, its energy consumption is mainly affected by weather. If the model of baseline energy consumption-influencing factors is used, it needs to know the heating season energy consumption and the corresponding temperature parameter, then establishes energy consumption regression model, thus obtains the energy saving.

Before establishing the regression model, the relationship between energy consumption and influence factors should be observed. After analyzing, there is a strong correlation between the energy consumption per unit area and Heating Degree Day.

Taking 2011.11.15 -2012.3.15 as a whole heating season, take half a month as a sample. 2011. The relationship between the energy consumption of sample points and cumulative value of the indoor and outdoor temperature difference is shown in Fig.1.

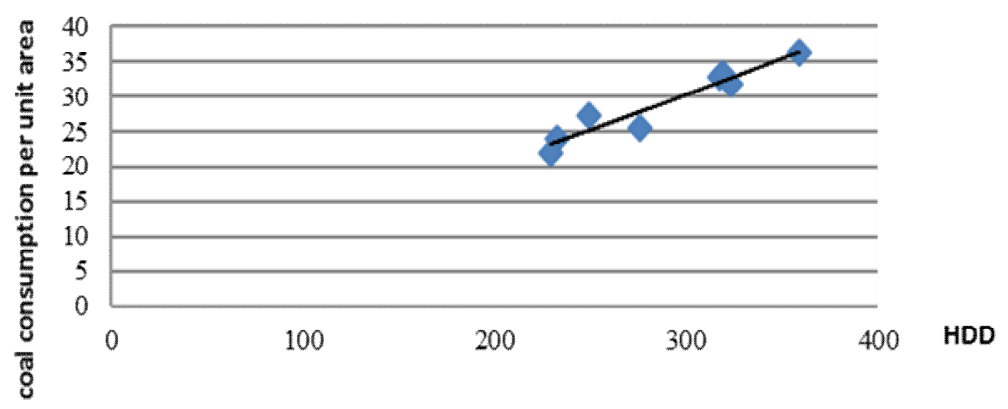

Fig.1 the relationship between the coal consumption per unit area and HDD

From the Fig.1, we can find that there is a strong correlation between the energy consumption per unit area and Heating Degree Day. Therefore, the calibrated baseline energy consumption model can be established by regression method.

Making regression model should choose professional statistical software, such as SPSS, SAS etc.

This project choose SPSS to establish the baseline energy consumption model, with a monthly coal consumption per unit area as the dependent variable (y) and cumulative value of the indoor and outdoor temperature difference $\sum \mathrm{t}_{\mathrm{d}}-\mathrm{t}_{\mathrm{w}}$ as independent variable(x). After using SPPS to regression the model, the results are shown in Table1. 
Table 1 Comparisons Between Model Summary and Estimate of Parameter

\begin{tabular}{c|c|c|c|c|c|c|c|c}
\hline \multirow{2}{*}{ equation } & \multicolumn{5}{|c|}{ Model summary } & \multicolumn{3}{c}{ Estimate of Parameter } \\
\cline { 2 - 10 } & $\mathrm{R}^{2}$ & $\mathrm{~F}$ & $\mathrm{df}_{1}$ & $\mathrm{df}_{2}$ & Sig. & Constant & $\mathrm{b}_{1}$ & $\mathrm{~b}_{2}$ \\
\hline second & 0.925 & 30.787 & 2 & 5 & 0.002 & 3.898 & 0.073 & $4.823 \mathrm{E}-5$ \\
\hline
\end{tabular}

Dependent variable: coal consumption per unit area

Independent variable is HDD.

It is shown in the Table 1, compare to the linear fitting, the second regression is with larger $\mathrm{R}^{2}$, namely the model has higher fitting degree, so it is suitable to choose second regression model.

The fitting degree $\mathrm{R}^{2}$ of this model is 0.925 , the $\mathrm{F}$ value is 30.787 , the sig value is 0.002 and the coefficient values of this model are:

$\mathrm{A}_{0}=4.823 \times 10^{-5}, \mathrm{~A}_{1}=0.73, \mathrm{~A}_{2}=3.898$

model: $\mathrm{E}=4.823 \times 10^{-5} \mathrm{t}^{2}+0.073 \mathrm{t}+3.898$

Model validation:

After establishing the model, the model should be verified. The verification includes the fitting degree $\mathrm{R}^{2}$ and the significance of model. The fitting degree and the significance of model $\mathrm{F}$ value can be calculated by professional static model, therefore, the model can be judged by the values calculated by software.

The $\mathrm{R}^{2}$ value is 0.925 . It means that the fitting degree of this model is good. Generally, the larger the $\mathrm{R}^{2}$ value is, the model can better reflect the relationship between independent and dependent variables. Although there is no rule for the minimum limit of $\mathrm{R}^{2}$, to consumption estimate models, $\mathrm{R}^{2} \geqslant 0.75$ is generally considered to be an acceptable range. ${ }^{[2]}$

The $\mathrm{F}$ value represent the significance of model, with a $90 \%$ probability (confidence), the $F_{\alpha}(p, n-p-1)=F_{0.1}(1,6)=3.78$. From the calculating result we can find that $F=30.787>F_{0.1}(1,36)$, so the model is of great significances.

Conclusion: the model is correct.

Calculating the Saving. Taking the 2012-2013 heating season as Reporting Period, the pump consumptions are not included because there is no retrofit for the water pumps.

Based on the outdoor temperature data, we can calculate each day's cumulative value of the indoor and outdoor temperature difference. Then the cumulative value of the indoor and outdoor temperature difference during the reporting period can be got, it is shown in Table 2

Table 2 Savings Calculation (standard coal, in: $\mathrm{t} / \mathrm{million}, \mathrm{m}^{2} / \mathrm{month}$ )

\begin{tabular}{c|c|c|c}
\hline Month & $\begin{array}{c}\text { Reporting-period } \\
\text { Consumption }\end{array}$ & $\begin{array}{c}\text { Baseline-Period } \\
\text { Consumption after } \\
\text { adjustments }\end{array}$ & savings \\
\hline November & 23.12803 & 25.47364 & 2.345608 \\
\hline December & 60.9892 & 70.50993 & 9.520725 \\
\hline January & 58.94878 & 70.45914 & 11.51036 \\
\hline February & 44.05046 & 54.01174 & 9.961285 \\
\hline March & 13.76152 & 18.69106 & 4.929546 \\
\hline Total & 200.878 & 239.1455 & 38.26752 \\
\hline
\end{tabular}


So the baseline after calibrated which all year coal consumption per unit area is $23.91 \mathrm{~kg} / \mathrm{m}^{2}$ $\mathrm{E}_{\mathrm{a}}=23.91 \mathrm{~kg} / \mathrm{m}^{2} \times 270$ million $\mathrm{m}^{2}=64569$ ton standard coal

According to the raw coal consumption and heating value recorded during the reporting-period, the coal consumption per unit area during reporting-period can be calculated.

The coal consumption per unit area during reporting-period is $20.09 \mathrm{~kg} / \mathrm{m}^{2}$.

$\mathrm{E}_{\mathrm{r}}=20.09 \mathrm{~kg} / \mathrm{m}^{2} \times 270$ million $\mathrm{m}^{2}=54237.06$ ton standard coal

$\mathrm{E}_{\mathrm{s}}=\mathrm{E}_{\mathrm{a}}-\mathrm{E}_{\mathrm{r}}=64569$ ton standard coal-54237.0 ton standard coal =10331.94 ton standard coal

The Calculation of Uncertainly. The uncertainty of a savings report can be managed by modeling errors, controlling random errors and data bias. Errors in mathematical modeling due to inappropriate functional form included of irrelevant variables, exclusion of relevant variables, etc. Sampling error arises when only a portion of the population of actual values is measured, or a biased sampling approach is used. Measurement errors arise from the accuracy of sensors, data tracking errors, drift since calibration, imprecise measurements, etc.

In order to communicate savings in a statistically valid manner, savings need to be expressed along with their associated confidence and precision levels. Confidence refers to the likelihood or probability that the estimated savings will fall within the precision range. For example, with a $90 \%$ probability (confidence) that the true-average savings value falls within $\pm 10 \%$.

The following calculation calculates in $90 \%$ confidence:

The modeling uncertainly is computed as follows:

Modeling Errors: $\mathrm{Y}_{\mathrm{y}}=\mathrm{t} \times \mathrm{SE}_{\mathrm{y}}$

Standard Error of regression: $\mathrm{SE}_{y}=\sqrt{\frac{\Sigma\left(\hat{\hat{i}_{i}}-y_{\mathrm{l}}\right)^{\mathrm{n}}}{n-p-1}}$

The Modeling Uncertainty: $U_{y}=\frac{F_{y}}{F_{1}}$

According to the static basic situation, it can be determined the basic information of the modeling errors: $n=8, p=1, \frac{a}{2}=0.1$. According to $t$-statistic, $t(0.1,1)=1.89$, the Standard Error of regression is 1.51 , the modeling Uncertainty is $7.85 \%$.

Sample uncertainly:

Sampling error arises when only a portion of the population of actual values is measured, or a biased sampling approach is used.

It is computed using the follow equation:

Sample uncertainly: $\mathrm{U}_{s}=\mathrm{t} \times \mathrm{SE}_{s}$

where:SE $=\sqrt{\left(1-\frac{n}{N}\right)\left[\sum_{i=1}^{n}\left(Y_{1}-P\right)^{2} /(n-1)\right] / n} ;$ n:The number of sampling; N:The total number of samples

Metering uncertainly: $U_{t}=\frac{\partial_{R} \times R}{t_{\left(\frac{G}{2}\right)}(w)}$ 
Where:

$\delta_{R}:$ a fraction of the maximum reading on the meter's scale;

$\mathrm{R}:$ scale of the chosen meter;

a:significance level;

$\mathrm{t}$ :infinitely many degrees of freedom, with a probability (confidence), the t-static is $2^{[3]}$.

The thermometer's fractional error is \pm 0.5 , the scale is 100 and the meter error is $9 \%$.

Combining Components of Uncertainty: $U_{E S}=\sqrt{U_{y}^{2}+U_{s}^{2}+U_{t}^{2}}$

Where:

$\mathrm{U}_{\mathrm{y}}$ : modeling uncertainly;

$\mathrm{U}_{\mathrm{s}}$ : sample uncertainly;

$\mathrm{U}_{\mathrm{t}}$ : metering uncertainly

The combination uncertainly is $11.9 \%$

According to the calculation, the result of savings is reasonable. The combination uncertainly is small. It means that the range defined for the estimate $( \pm 11.9 \%)$ will contain the true value for the whole group (which is not observed) with a probability of $90 \%$.

\section{Conclusion}

1) The model of baseline energy consumption-influencing factors method established the mathematical model through the coal consumption and main factors, through the statistics and the actual samples to ensure the goodness of fit indexes. It also unifies the external conditions before and after the retrofit and finally gets the method to calculate savings. This method is more accurate, considering various influencing factors of the energy consumption, not only split the savings, so the error is small, and the method is of high reliability.

2) Analyze the factors influence the heating system energy consumption, selecting indoor and outdoor temperature difference (HDD) as the independent variable, establishing the model of baseline energy consumption-influencing factors, putting forward the method of calculating heating system's energy saving through the statistics and the actual samples to ensure the optimal degree of model, and analyzing the uncertainty.

3) Through retrofitting example in Beijing, put forward the feasibility to calculate the energy section of the heating system, establishing the mathematical model through calculation. The results show that the indoor and outdoor temperature (HDD) can well reflect the change of energy consumption of heating system.

4) Verifying the feasibility through examples provide empirical basis for energy saving heating system calculation and verification.

\section{References}

[1] Zhangqi.The management research about the energy-saving renovation of existing building[D].Tianjin University.2010.12-13

[2] Wu Jun Feng. The method of measurement and verification of energy saving central air conditioning system based on multivariate statistical techniques [J]. Heating ventilating \& air conditioning 2014.44(1):127-129 
[3] National Quality Technology Supervision Bureau Metrology Department. Evaluation and expression of uncertainty in measurement guide [M]. Beijing: China Metrology Publishing House.2004:53-55 